\section{EMBRYARIDDLE}

Aeronautical University

SCHOLARLY COMMONS
Journal of Aviation/Aerospace

Education \& Research

Volume 8

Number 3 JAAER Spring 1999

Article 8

Spring 1999

\title{
The Airline Maintenance Mechanic Educational Infrastructure: \\ Supply, Demand, and Evolving Industry Structure
}

Robert N. McGrath

Blaise P. Waguespack

waguespb@erau.edu

Follow this and additional works at: https://commons.erau.edu/jaaer

\section{Scholarly Commons Citation}

McGrath, R. N., \& Waguespack, B. P. (1999). The Airline Maintenance Mechanic Educational Infrastructure: Supply, Demand, and Evolving Industry Structure. Journal of Aviation/Aerospace Education \& Research, 8(3). https://doi.org/10.15394/jaaer.1999.1225

This Article is brought to you for free and open access by the Journals at Scholarly Commons. It has been accepted for inclusion in Journal of Aviation/Aerospace Education \& Research by an authorized administrator of Scholarly Commons. For more information, please contact commons@erau.edu. 


\title{
THE AIRLINE MAINTENANCE MECHANIC EDUCATIONAL INFRASTRUCTURE: SUPPLY, DEMAND, AND EVOLVING INDUSTRY STRUCTURE
}

\author{
Robert N. McGrath and Blaise P. Waguespack
}

There is an encroaching crisis in the supply and demand of aviation maintenance labor. This paper reports results of a survey of FAA-licensed A\&P schools and a survey of airlines and major maintenance outsourcing firms. Results largely confirm general expectations. Further analysis found indications of an impending shakeout in the extant training infrastructure. Strategies centered on tapered vertical integration are offered as an admittedly imperfect industry-wide solution.

Trends in the civil air transport (airline) industry make clear that rapid growth is practically inevitable. Because of factors such as the spread of free-market philosophies and the consequent globalization of industries in general, it has been predicted that the total miles flown will rise rapidly in the foreseeable future ("Service," 1998). This has driven a rise in demand for new aircraft, but the rising demand for new aircraft far exceeds the manufacturing sector's ability to keep up, and many airlines now ordering new aircraft must wait years for delivery ("Manufacturing," 1998). Consequently, the already aged and continuously ageing worldwide fleet will be taxed by an increasing number of operating hours and cycles which, in addition to number of aircraft and preventive maintenance requirements, are main strategic predictors of aircraft maintenance (Friend, 1992).

Looking ahead in terms of maintenance, then, it at first seems fortunate that a state of immense industry maintenance facility overcapacity currently exists, and will continue to exist (Ionides, 1999). By one estimate, the current worldwide demand for maintenance services is about $\mathbf{5 8}$ million laborhours, while the industry is actively providing about 77 million, with a current possible total capacity of 155 million labor-hours in the industry is available. In the year 2005, demand is forecasted to be about 79.5 million labor-hours, while total industry capacity will still exceed 181 million labor-hours (McKenna \& Scott, 1997).
But apparently, "labor-hours" as a measure of industry capacity has more to do with physical plant than actual labor. Forecasts also indicate that over the same period, the supply of mechanics with Airframe and Powerplant (A\&P) Certificates might become very strained, with some areas already reporting difficulties finding skilled mechanics and engineers (Gallacher, 1999; Shay, 1999). While the growth in demand for A\&Ps between now and 2004 is estimated to be close to 34,000 , attrition alone is expected to be about 40,000 (Jackman, 1996). Though there is probably enough training capacity to support the industry, it is less certain that the right structure of incentives exists to draw in the needed new technicians in the near future. Also, these aggregate figures do not take into account obvious heterogeneities in supply and demand such as match-ups among, for example, specific skills of individuals and related requirements of specific organizations.

Thus, ironically, airline maintenance organizations as well as independent providers of outsourced Maintenance, Repair and Overhaul (MRO) services, Original Equipment Manufacturers (OEMs), and other recent entrants into the MRO field look to become squeezed by the pressure to achieve and maintain high rates of asset utilization (in periods of overcapacity, typically accomplished through lowering one's prices), and the pressure to maintain desired levels and types of maintenance skills and resulting service quality. What this shortage forebodes is a supplier's market where the price 
of maintenance labor will likely be bid upwards. In other words, maintenance organizations will likely find themselves competing with each other for the right technicians (exacerbating their direct and some indirect labor costs,) while at the same time the prices these providers will be able to charge their customers for maintenance services will simultaneously be pressured to fall as long as aggregate maintenance overcapacity exists. This condition, of course, will be present in an environment that is already very competitive in more ordinary terms ("MRO Competition," 1996).

In the United States, at least, many people feel that unrestrained free market forces will ultimately resolve dilemmas of this type. For example, one might assume that the coming disparity between the demand for maintenance labor and its supply will bid up the average wage for maintenance services, and that this should directly incentivize a correct rate of entry by people of the right skills from the general working population, and that labor supply and demand will equilibrate in textbook fashion, right on time. On the other hand it could also be argued that airworthiness is something of a public good, and that an optimal strategy for the airline industry at-large would involve innovations that improve the productivity of the existing workforce. Such changes could include equipment upgrades (planes and engines) that improve the reliabilities of the equipment and decrease the need for basic maintenance, and/or make proactive improvements to the existing industry training infrastructure that produces maintenance technicians.

In short, it is perhaps the case that conditions of poor, problematic, or just heterogeneous maintenance quality among maintenance providers in the airline industry do not enhance overall industry vitality. At some point in the debate, many feel that cooperation, rather than (or in addition to) competition, is a more enlightened tack. Indeed, it has become plain that in some aspects of business, cooperation through instruments such as consortia, alliances, and more permanent forms of partnering has become popular, profitable, and conducive to the greater socioeconomic good, even in areas traditionally earmarked by stiff competition (Phillips, 1997).

These perspectives are obviously arguable, even among professional economists and public policy practitioners. It is not the authors' immediate purpose to participate in a theoretical advancement of the argument, but to accept the reality of the encroaching problem and present the initial results of a research collaboration between two institutions in the airline industry maintenance training infrastructure. Observing developments in this collaboration, even from the earliest phases, will hopefully contribute to the ongoing resolution of the labor shortages and skill heterogeneity in the industry. After all, the best managers foresee problems and have solutions ready when difficulties arrive.

\section{THE STUDY}

Researchers in the Business Administration Department at Embry-Riddle Aeronautical University were approached by a major U.S. airline to help investigate the nature of a forecasted shortfall of Airframe and Powerplant (A\&P) mechanics, expected to become especially critical for that airline around the year 2000. At that time the airline expects that about $25 \%$ of the maintenance workforce will attrit or retire; especially retire, meaning that the proportion of experience lost would be even worse. Up to $42 \%$ of related management could be lost. These trends were known to be determined by internal labor market factors which were largely beyond any realistic control, so management at the airline opted to search for knowledge about external patterns which could contain opportunities for innovative solutions.

The research was lead by a Professor of Marketing and Business Research Methods, who organized graduate students enrolled in an MBA in Aviation course, into teams which performed highty structured telephone surveys. The survey instruments were developed in consulation with: (1) the airline, represented by a former line technician and A\&P holder now a financial analyst and a representative from the Human Resources department specializing in technician employment, (2) a Professor of Strategic Management who is an instructor in the area of Aviation Maintenance Mangement and former Air Force Officer responsible for engine maintenance programs; (3) students in the class, which included two A\&P holders, one an avionics instructor at the university and (4) and a review of the applied and trade literature.

Two telephone surveys were conducted in the Spring of 1998. The first queried airlines as well as major providers of outsourced aircraft maintenance. Participants were identified before the research began on the basis of market share and total volume in consultation with the airline representative. The general purpose was to ascertain current A\&P labor conditions and associated expectations. This was a survey of some of the present and future demand characteristics of A\&P 
labor.

The second survey queried institutions granting A\&P certificates and conducting related maintenance training consistently over a period of 20 years. FAA Advisory Circulars since 1979 were canvassed for this purpose, the latest being AC 147-2DD issued in March 1997. The general purpose was to (a) reaffirm the FAA census, and (b) ascertain the nature of the current maintenance training infrastructure. This, in essence, was a survey of some of the characteristics of the supply of A\&P labor. Results are described in the following section.

\section{RESULTS}

The following carriers agreed to participate in the survey of A\&P labor demand:

$\begin{array}{ll}\text { Alaska Airlines } & \text { American Airlines } \\ \text { America West Airlines } & \text { Continental Airlines } \\ \text { Delta Airlines } & \text { DHL Airways } \\ \text { Northwest Airline } & \text { Southwest Airlines } \\ \text { Trans World Airlines } & \text { United Parcel Service } \\ \text { US Airways } & \text { Air Tran Airways } \\ \text { Hawaiian Airlines } & \text { Midwest Airlines } \\ \text { Reno Air } & \text { Horizon Air } \\ \text { Business Express } & \text { Evergreen }\end{array}$

The following maintenance providers (outsourcing firms) also agreed to participate:

$\begin{array}{ll}\text { Aero Corporation } & \text { Aero Union } \\ \text { Aircraft Support and Parts } & \text { Associated Air Centre } \\ \text { Avtec } & \text { Hamilton Aviation } \\ \text { Midcoast } & \text { Mobile Aerospace } \\ \text { Pemco } & \text { BF Goodrich Aerospace } \\ \text { Santa Barbara Aerospace } & \text { Commodore Aviation }\end{array}$

TIMCO

With respect to the survey of A\&P labor supply, it was of immediate interest that not all schools identified in FAA Advisory Circulars were still in operation. First, it was noted that while one authoritative source indicated the presence of 220 schools (United States Department of Transportation \& FAA [USDOT \& FAA], 1993), only 185 were listed in the most recent FAA circular. Of these 185 schools, 164 agreed to participate. Two declines to participate, three were exiting the training industry because of low enrollment, and the remainder could not be contacted.

In participating in the survey, there was some slight variation in which firms answered which questions. In other words, participation was enthusiastic, but not all firms would or could hazard an answer to each question. However, summary participation in each question was very high, so slight variations do not threaten the modest purposes of this paper.

Table One and Table Two presents results of both surveys. Some editing of the questions was needed to be concise here, but the tables capture the intent of each question as asked on the survey instrument. The Tables present the questions in the order they were asked during the phone interview. Information not indicated in the tables (as noted) is as follows.

In the survey of demand (Table One), in question 4 (Do you confer A\&P licenses?), it was interesting that three carriers required trainees to successfully complete training within a specified time frame; specifically, two carriers required completion within six months, and one within 18 months. Four outsourcing firms that conferred A\&P licenses also gave trainees deadlines; specifically; one required completion within six months, two within 12 months, and one within 24 months. With respect to questions five and six, firms were permitted to specify more than one main source of A\&P applicants, and more than one target of $A \& P$ recruiting, so percentages total above 100 . With respect to questions 11,12 , and 13 , participants were encouraged to make additional comments. Of those firms that chose to comment, criticisms of new hires (question 11)' tended to focus on overall inexperience, low skill levels, and lack of needed specialized skills. Comments about other noticeable problems (question 12) tended to focus again on lack of experience, and a lack of avionics and electrical skills. Further elaborations (question 14) repeated these themes, plus evidenced general concerns about present supply/demand imbalances (overall A\&P shortages), devolving skill levels, and the siphoning off of the best talent to the largest operators.

\section{SURVEY ANALYSIS}

Demand. Even a cursory examination of the questionnaire data yielded interesting results. First, and as probably would be expected, the airlines were much larger organizations than the outsourcing firms, measured as the mean number of mechanics and A\&Ps; 2,817 mechanics and 1,920 A\&Ps for the airlines to 318 mechanics and 203 A\&Ps, for the MROfirms. Importantly, such a difference in size is indicative of an imbalance in the bargaining power for labor, much favoring the airlines.

Standard statistical tests were used to gain a better 
understanding of the differences in other data. Percentages of yes/no answers were evaluated as tests of standardized frequencies using the chi-square statistic (Lapin, 1981). Differences between population means were evaluated by employing the Student $\mathbf{t}$ statistic, in a method specifically suited for small sample sizes. The most conservative assumptions were made; i.e., tests were two-tailed (Lapin, 1981).

The airlines and the outsourcing firms were found to be significantly different in the following ways. On balance, the pattern indicates that the airlines are willing to exercise their bargaining power:

-- Question 1: In contrast to what the large differences in means $(2,817 \mathrm{v} .318$, and $1,920 \mathrm{v}$. 203$)$ might intuitively indicate, airlines employed mechanics at only a slightly higher rate $(t=2.25$, greater than the threshhold of 2.048 at alpha $=.25$ ). The rate at which the two groups employed A\&Ps was, actually, very marginally nonsignificant $(t=1.90,<2.056)$. While the means indicated an extreme difference, in other words, small sample sizes and wide variances around the means made the "apparent," wide differences between statistically non-significant.

-- Question 2: Outsourcing firms were slightly less likely to perceive self sufficiency (at $\mathrm{df}=1$ and alpha $=.05$, the chi-squared threshold was 3.841 ; chi-squared $=4.00$ ).

-- Question 3: The airlines were much more highly unionized (chi-squared $=43.12$ ).

-- Question 4: Airlines were much more likely to require applicants to possess licenses (chi-squared $=43.12$ ).

-- Question 5: Because of the "in-house" category ( $11 \%$ for airlines and $42 \%$ for outsourcing firms), the main source of job applicants was likely to be different (at $\mathrm{df}=4$ the threshold was 9.488; chi-squared = 19.36).

-- Question 6: Because of the "VoTech" category (61\% for airlines and $25 \%$ for oursourcing firms), recruiting patterns were likely to be different (at $\mathrm{df}=8$ the threshold was 15.507; chi-squared = 38.55).

-- Question 7: The airlines were more likely to require a written employment exam (chi-squared $\mathbf{3} 3.76$ ).

-- Question 13: Oursourcing firms were slightly more likely to foresee an increase in the future demand for A\&Ps (chi-squared = 6.18).

-- Question 16: Outsourcing firms were slightly more likely to have plans for conducting in-house training of A\&Ps (chi-squared $=6.40$ ).
The two populations were not found to be significantly different in terms of

-- Question 2: The number of additional A\&Ps needed $(\mathrm{t}=1.67,<2.160)$.

-- Question 8: Requirements for a practical exam (chi-squared $=.04$ ).

-- Question 9: Requirements for a probationary period (chi-squared $=.30$ ).

-- Question 10: Base and overtime pay ( $t=1.08$ for both parts, $<2.056$ and 2.093 , respectively).

-- Question 11: Perceptions of problems with the skills and knowledge of new-hires (chi-squared $=4.50$ ).

- Question 12: Perceptions of other problems with new-hires (chi-squared $=1.56$ ).

-- Question 13: Percentage increase in A\&Ps forecasted $(\mathrm{t}=1.56,<2.056)$.

-- Question 15: The presence of training partnerships and alliances (chi-squared $=1.54$ ).

-Question 17: Percent of applicants passing initial job screening $(\mathrm{t}=1.16,<2.048)$.

Supply. Referring to the results of the questionnaire given to the Part 147 Schools (Table Two), it was interesting that an overwhelming number of schools provide what seem to be generalist A\&P licenses, in the sense that almost $85 \%$ conferred only A\&P licenses, while much smaller percentages offered only an "A," a "P," or all three possibilities of A, P, and A\&P. More telling, perhaps, was that only about $28 \%$ tailored their programs to specific clients; and here, it is worth noting that most of this percentage was really only "specific" to categories of clients (such as airlines or general aviation), not specific organizations. In light of the demand described above, such an aggregate lack of focus could indicate a suboptimal degree of "closeness to the customer," or coordination with the needs of the consumers of maintenance labor -- despite a contradictory conclusion which might be inferred from noting that about half maintained training partnerships/alliances, and internships/co-op programs.

There were signs of stability and uniformity in the training infrastructure. Over $90 \%$ of new A\&Ps were evidently coming from a concentration of three main sources: in order, Community Colleges, VoTech schools, and Universities. Almost two-thirds of the sample were state-supported. Again, about half had internship/co-op programs, $88 \%$ offered financial assistance programs, and $91 \%$ offered job placement 
assistance. Most (85\%) foresaw an increase in future enrollment.

More worrisome was the variation in exam pass rates and attrition rates. The exam pass rate varied from $15 \%$ to $100 \%$, with a mean of $92.2 \%$. The attrition rate varied from $0 \%$ to $90 \%$, with a mean of $19 \%$. The observer is immediately compelled to speculate as to some of the possible causes of such variation, given the high level of guidance and oversight provided by the FAA. For example, some schools could be much more difficult than others for a wide variety of reasons; and/or schools could vary considerably in their quality. Or large heterogeneities could exist in student populations, though this seems more doubtful. Other reasons could exist as well. Otherwise, there were additional signs of fragmentation and wide variation in the training infrastructure. Most telling was that the largest school was delivering about 350 A\&Ps a year, or about $.03 \%$ of the 11,000 A\&Ps which enter the field annually ("Pilots," 1993). Most other schools were much smaller still. Very few, then, could be theoretically ascribed much bargaining power, but it must be conceded that it might be senseless to allude to the bargaining power of schools since individuals, not schools, bargain for the sale of maintenance labor. On the other hand, it is within the first author's professional interest to be well aware of just how much common sense A\&P trainees employ in making careful and calculating evaluations of which schools are worth attending, so the point is much the same.

One-fifth of the sample was tuition-driven; tuition ranged widely from $\$ 500$ to $\$ 32,000$, with a mean of about $\$ 6,864$. The duration of programs ranged from 10 months to 60 months, with a mean of 22.4 months. Experience in training in aviation maintenance ranged from 1 to 70 years, with a mean of 31.3. Class sizes ranged from about 4 to 50 ; some schools employed only part-time instructors, while other schools employed only full-time instructors. However, it might be a matter of perspective as to whether these conditions represent a lack of coordination and standardization, or merely a healthy variety. If the latter is assumed, however, then it becomes puzzling why only $28 \%$ tailor their programs to specific clients.

\section{DISCUSSION}

This paper opened with a general description of the muchimproved health of the aviation industry as a whole, but quickly pointed to an impending shakeout in MRO because of a squeeze between intense pressures to economize versus escalating labor costs. The data suggests that the training infrastructure, as well, may be poised for a similar shakeout, or at least a rationalization and restructuring. The reasoning follows, with alternative strategies for its management.

Though the demand for A\&P mechanics may become critical in the future, that situation has not yet arrived. In the near-term, it looks as if maintenance schools will continue to struggle for enrollment. The finding that $85 \%$ of schools foresee an increase in near-term enrollment may contain an optimistic bias. At least, the airlines and maintenance outsourcing firms were not nearly as optimistic that they would be able to satisfy their future needs. Of course, it may simply be that the demand is rising faster than the supply is rising (but that both are indeed rising), which would accommodate everyone's predictions.

But another (or additional) possibility is to first note that the number of schools has begun to decline. The recent population of schools may have been as high as 220 (USDOT \& FAA, 1993). In 1994 the number of reported Part 147 schools was 193. That number has since decreased and the most recent data indicated 185 schools remaining, and the phone survey found two more schools poised to exit. So if the demand for technicians is rising, the decline in the number of schools warrants an explanation.

Understanding some of the more classic dynamics of industry evolution helps (Porter, 1980). When industries/markets are growing, it is normal for individual firms to do what is necessary to grasp larger portions of market share, or to at least keep up with industry growth at least in absolute terms. However, when industry/market growth eventually subsides, and providers of resources to that market continue to expand, the aggregate capacity in the supply of resources eventually exceeds aggregate market demand, leaving the supplier industry at-large in a condition of overcapacity. Dividing up a stable market among providers who, on average, have more capacity than the market has demand, leaves providers in a bad cost crunch. Earlier, it was described how MRO firms are in such a situation.

Very similar forces apply to the training infrastructure that supplies MRO with labor; except a shakeout due to poor capacity utilization looks like it will be caused by the scarcity of raw materials (students), rather than a paucity in demand. But there is more. Conditions are changing in ways that suggest that the major employers of A\&Ps are not willing to settle for poorly trained mechanics, almost no matter how 
scarce they might become.

Classically, when "buyers" (in this case, airlines and outsourcing firms) are sophisticated (as, apparently, are recruiters and human resources personnel) and can make finetuned assessments of the VALUE of resources being acquired (in this case, new A\&Ps), two generic types of firms (in this case, schools) tend to survive; firms that are poised to deliver high-quality, highly-differentiated, high-value-added products/services, and those that are poised to undercut everyone else in terms of cost, and generally price (Porter, 1985). The providers (schools) which can not deliver either high-quality/high-differentiation-at-a-good-price, $O R$ a lowcost, ostensibly low-price good/service, are positioned to fail and exit. In short, buyers (airlines and other consumers of maintenance labor) should be expected to rationalize-out the overcapacity (of schools) over time, forcing the relatively poor value-adders (mediocre schools) to exit.

This may be what has already begun to occur in the A\&P training infrastructure. As the supply of people entering the A\&P field falls, but as the demand rises, increasingly sophisticated recruiting efforts of the airlines/others should be expected to target what each firm, given its challenges and strategy, will deem appropriate value in a new-hire. One can not assert with much confidence that airlines and major outsourcing firms will do nothing about the impending labor crisis except preparing to outbid one another. Wisely focusing on value, not volume, at least some will be keenly interested in hiring only the best mechanics, adjusting to remaining labor inadequacies by substituting inferior-quality labor for technological improvements in the inherent maintainability of equipment (and, ultimately, dispatch reliability), and/or by making managerial innovations that improve the productivity of the maintenance workforce.

In other words, the nature of the demand indicated in these surveys indicates that buyers of maintenance services are not interested in just getting "warm bodies." Respondents consistently voiced as much, if not more, concerns about the skills and competencies of future technicians as about the potential number of technicians. As one might expect, the airlines, firms with deeper pockets and better bargaining positions for labor, showed less anxiety than the outsourcing firms. Several long-term results of this situation should be, to those who have faith in the invisible hand of the forces behind supply and demand, that (a) on the demand side, there will continue to be a siphoning-off of the best talent to the airlines and other areas where the need for maintenance labor is highly concentrated in pwerful firms (consolidating, global players in MRO, OEMs, etc.), and (b) on the supply side, either the highest-quality, or the most cost-effective schools (or perhaps both, if ingeniously managed) should survive an encroaching shakeout which, as stated, may have already begun. In the long run, the high-cost/high-value-adding schools may gravitate to serving the airlines, while the low-cost schools may gravitate to general aviation and less-wealthy aviation segments.

It is arguable, however, whether this is socioeconomically optimal. Maybe the best mechanics should go to the firms with the greatest exposure to the general public, and that this should actually be encouraged. Or, one might argue, ordinary market dynamics should be left to sort it out, and that there should be no additional institutional creation impeding equal access to labor markets. In a way, the issue seems to revolve around equality (equal access), and equity (fairness on all accounts), which can not be decided here.

At any rate, schools may be individually correct that future enrollment will increase, but if this is mostly because other schools are simply exiting the training infrastructure. The situation may not necessarily be that the total supply of mechanics will increase, or that the benefits will be equitably distributed throughout the industry. But, as some schools and institutions leave the field, others now see a chance for their enrollements to increase.

Short of being able to significantly alter the aggregate number or the quality of the people interested in becoming aviation mechanics, the authors suggest that one way to embark upon a less painful rationalization of the extant training infrastructure is for the demand-side to consider vertical/backward integration, or at least tapered or quasiintegration, and for the supply-side to do some keen analysis of the value they individually deliver, and hone products to the demands of most likely buyers, for example through more focused curricula and partnering (complementary forward integration).

Backward integration refers to any decision aimed at restructuring an arrangement with one's suppliers that attempts to reduce supply-related uncertainties. Outright acquisition of one's supplier is one example, as is deciding to enter the upstream business through internal growth. Of the known possible benefits of vertical integration, some that seem to especially pertain to the present situation include: 
economies of combined operations, improvement in the ability to trust the supplier, greater economy of monitoring the supplier for adherence to expectations, better assurance of a steady flow of supply, a reduction in overall slack, reduction in purchasing costs and bargaining, better capital utilization, enhanced ability to fine-tune and differentiate the overall product/service, and full capturing of the profitability of the supplier. Potential costs include: increased operating leverage (too many eggs in one basket), reduced flexibility to environmental change, capital investment (justifying hurdle rates and opportunity costs of capital), foreclosure of alternative sources of supply, maintaining balance in potential capacity differentials, dulled market/consumer incentives of a captive relationship, the distraction/dilution of managerial talent and organizational competencies, and the possibility of a "bad apple" phenomenon, or the vulnerability to contamination of one organization by another organization's inferior performance standards (Porter, 1980).

But organizations are apt to partially, as well as fully, integrate backward when the combinations of benefits and costs suggest it. Tapered integration generally refers to a strategy of becoming one's own supplier, but not supplying all of one's own demand (as opposed to full integration). Potential advantages include a lower elevation of fixed costs, reduced risks of locking-in to one supplier, the maintenance of some market discipline on the captive supplier, the development of a detailed understanding of relevant costs, and the ability to still externalize the risks of fluctuations in demand (Porter, 1980). For example, an airline could acquire an existing Part 147 school (and in impending conditions, at a very attractive price), or open its own training academy, to fulfill its minimum forecasted needs for maintenance labor, accommodating upswings in business cycles through external recruiting -- meanwhile tailoring the academy's program to the specific operational requirements of the airline, and making efficient use of everyone's time and other resources.

Quasi-integration has a similar intent, but generally refers to a mutual investment (hence financial stake) between firms who share a common goodwill, and who contact each other frequently in the natural course of their relationships. Advantages, again, can be found in various cost economies, the absence of any necessary exclusive commitment to either supply or purchase, and a lower overall capital investment. For example, a major consumer of maintenance labor might directly invest in an existing school, technically maintaining its business independence but otherwise enjoying the benefits of a very high level of cooperation and coordination, all lubricated most importantly by mutual goodwill.

Given the mutual goodwill that obviously exists between the training infrastructure and its customer base, quasi-integration might be the theoretically more correct paradigm to pursue. Obviously, since each consumer of maintenance labor is potentially idiosyncratic, and as there seems to be so much variation in the supplier base, permutations of solutions are almost endless. It is left to individual strategists to consider their own requirements.

In addition to achieving firm-level benefits, the industry as a whole might benefit from a trend towards forward and backward integration. Overall training capacity could be maintained, instead of severely shaken-out and generally injured in the short-term, to the detriment of being able to satisfy long-term growth in demand. But remaining capacity could be rationalized around, and tailored to, the specific needs of buyers, on a case-by-case basis, rather than providing an undersized population of generalists who apparently are not optimally valuable new-hires.

However, caveats are certainly in order as well. As stated ealier, a trend toward integration could leave the consumers of maintenance labor who do not have the ability to integrate in an only greater predicament. General aviation and fixed-base operators may become particularly strained, or economically locked-out from fair access to the high-cost/high-value adding schools, settling to recruit at what has sometimes been referred to as the "diploma mills" ("A Greater," 1996).

\section{CONCLUSION}

Globalization will continue to change the structure of the aviation industry at many points of value-addition throughout its complete supply chain. Education/training is a supplier industry that is just as vulnerable to the forces of supply and demand as its downstream customers. In addition to globalization drivers, the simple scarcity of a key resource -skilled labor -- will shape industry restructuring as well. Proponents of "free market" solutions should be aware that the smartest entrepreneurs respond proactively to foreseeable changes; they do not wait for gross dis-equilibria to trigger reactive equilibration, at serious socio-economic cost. $\square$ 
Table One - Survey of Airlines and MRO Firms: Demand Survey

1. How many mechanics are currently employed? How many licensed A\&Ps are employed?

2. Is the number of A\&Ps sufficient for present needs?

If not, how many more A\&Ps do you need?

3. Is maintenance unionized?

4. Do you require applicants to have an A\&P license? If not, do you train A\&Ps (grant licenses)?

5. What are the sources of A\&P job applicants? (respondents asked to check all that applied)

6. What is the main target of A\&P recruiting? (respondents asked to check all that applied)

7. Do you require a written employment exam?

8. Do you require a practical employment exam?

9. Is there a probationary period for new-hires?

If yes, how long in (months)?

10. What is the starting A\&P base pay ( $\$ / \mathrm{hr}$.$) ?$

9 What is starting A\&P overtime pay?

11. Do you have problems with skills \& knowledge Of new-hires?

12. Are there any other noticeable problems?

13. Do you foresee an increase or decrease in number of A\&Ps needed in the U.S. airline industry? If yes, by what \%?

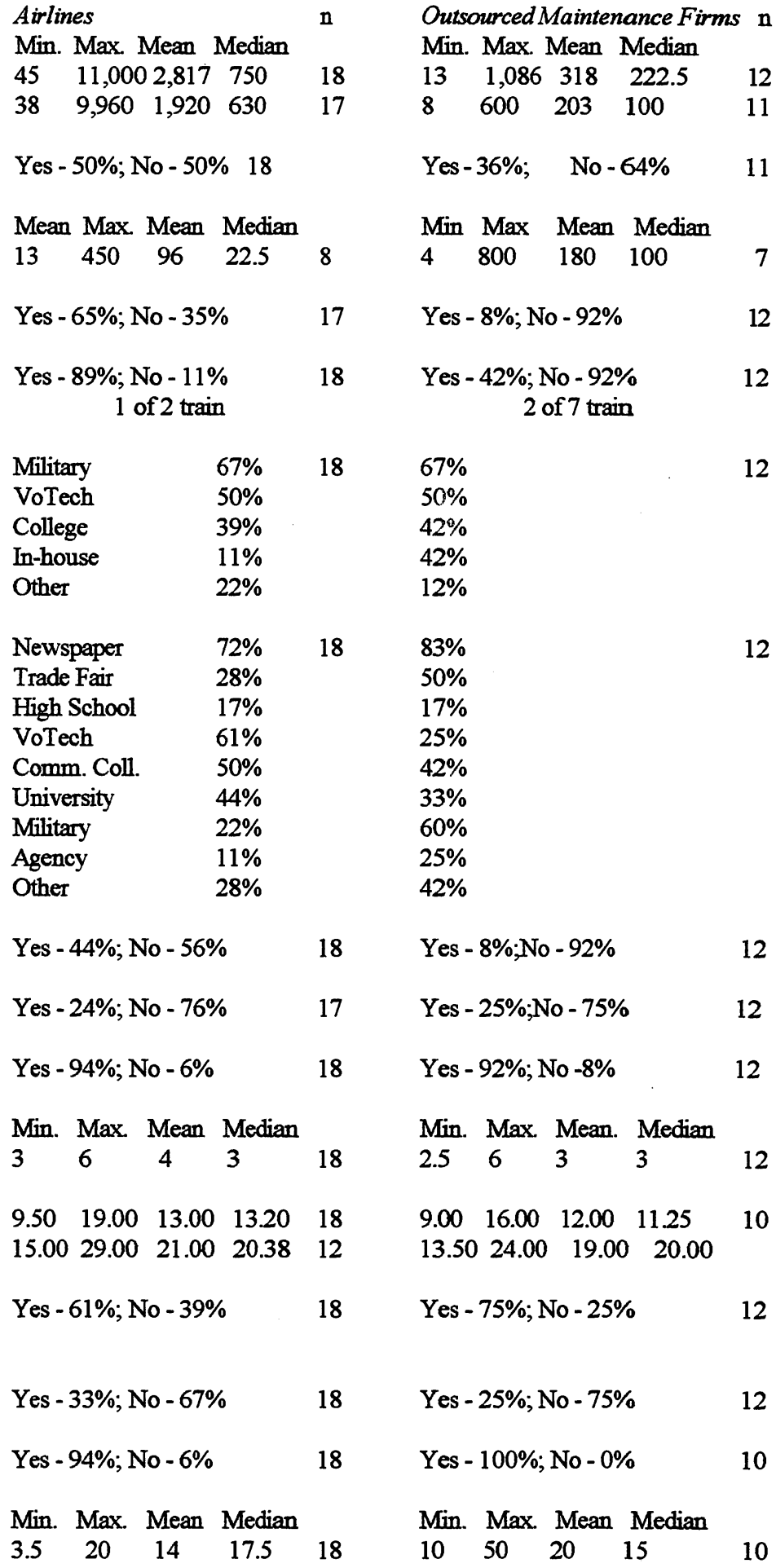


14. [Qualitative descriptions of concems]

15. Do you maintain A\&P training partnerships/alliances?

16. Do you have plans for in-house, formal A\&P training?

17. What $\%$ of applicants pass initial job screening?

18. What $\%$ of applicants identified as qualified are hired?
See text.

Yes - $17 \%$; No - $83 \%$

Yes - $11 \%$; No - $89 \%$

Min. Max Mean Median

$\begin{array}{lllll}3 & 90 & 44 & 36 & 18\end{array}$

3
See text.

18 Yes $-25 \%$; No $-75 \%$

12

18 Yes $-25 \%$; No $-75 \%$

Min. Max. Mean Median

$\begin{array}{lllll}18 & 3 & 80 & 31 & 20\end{array}$

$\begin{array}{lllll}13 & 1 & 100 & 60 & 70\end{array}$


Table 2 - Survey of FAR Part 147 Schools: Supply Survey

1. Which FAA AMT licenses do you confer?

2. Classification of your program.

3. Major source of funding.

4. Duration of A\&P program (in months).

5. A\&P student/faculty ratio.

6. Number of full-time instructors Number of part-time instructors

7. Tuition (excluding dorm (\$).

Additional fees?

If yes, how much?

8. Financial aid available?

9. Internships/Co-ops offered?

10. Do you offer job placement assistance?

11. Is the program tailored to specific clients?

12. A\&P exam pass rate.

13. Attrition rate.

14. Years of experience training aviation maintenance.

15. How many students successfully complete annually?

16. Do you foresee an increase or decrease in enrollment In the next three years?
Airframe Powerplant

$.62 \% \quad 7.48$

A\&P

84.47

All n

$12.42 \quad 161$

$\begin{array}{ll}\text { High School } & 4.88 \% \\ \text { VoTech } & 32.32 \% \\ \text { Comm. College } & 39.63 \% \\ \text { University } & 18.29 \% \\ \text { Other } & 4.88 \%\end{array}$

$\begin{array}{ll}\text { State Govt. } & 65.89 \% \\ \text { Federal Govt. } & 3.88 \% \\ \text { Tuition } & 20.93 \% \\ \text { Industry } & 4.88 \%\end{array}$

$\begin{array}{ll}\text { Min. } & \text { Max. } \\ 10 & 60\end{array}$

60

Mean

22.6

4

50

16

0

0

500

57

13

5.5

2

$32,000 \quad 6,862$

Yes - 80\%;

No - $20 \%$

30

2,950

931

Yes - $88 \%$; $\quad$ No $-12 \%$

Yes - 45\%;

No $-55 \%$

Yes - 91\%;

No $-9 \%$

Yes - 28\%;

No $-72 \%$

Min.

$15 \%$

Max.

$100 \%$

Mean.

$92.2 \%$

$0 \%$

$90 \%$

$19 \%$

70

31.3

5

350

$41.9^{\circ}$

Increase - $85 \%$

Decrease - 7\%

No change - $8 \%$
129

160

147

163

164

163

163

150

147

164

154

164

164 
Dr. Bob McGrath is an Assistant Professor in the Department of Business Administration at Embry-Riddle Aeronautical University in Daytona Beach, Florida. After graduating from the Air Force Academy, he served five years as a maintenance officer. He then worked for Texas Instruments, General Electric Aircraft Engines, and the Lockheed Aeronautical Systems Company as a logistics analyst, service engineer, and program manager, respectively. He earned his Ph.D. at Louisiana State University and now teaches and researches in the area of strategic and technology management.

Dr. Blaise P. Waguespack, Jr. graduated from the University of North Texas with a Ph.D. in Marketing and is currently an Assistant Professor at Embry Riddle Aeronautical University. Previous works written by Dr. Waguespack have been published in the Journal of Transportation Management, Managing Service Quality and other international and national conference proceedings. Dr. Waguespack has conducted research for UAL, Continental Airlines, and Allied Signal among major aviation and aerospace firms, while his personal research interest are in the areas of Service Marketing, Airline Alliances and Airport Customer Service issues.

\section{REFERENCES}

A greater threat than terrorism? (1996, September 9). BusinessWeek, 87-88.

Friend, C. H. (1992). Aircraft maintenance management. UK: Longman Scientific and Technical.

Gallacher, Jackie (1999, March). Third party pressure. Airline Business, 48-50.

Ionides, Nicholas (1999, March). Asia faces fallout. Airline Business, 57-58.

Jackman, F. (1996, January/February). Maintenance training. Overhaul \& Maintenance, 43-44.

Lapin, L. L. (1981). Statistics for modern business decisions. (3rd ed.). New York:

Harcourt-Brace.

Manufacturing: Aerospace prognosis 1998. (1998, January 12). BusinessWeek, 106.

McKenna, J. T. \& Scott, W. B. (1997, April 14). MRO's challenge: Quality vs. Cost. Aviation Week and Space Technology, 44-45.

MRO competition intensifies. (1996, June 24). Aviation Week and Space Technology, S1-S11.

68.

Phillips, E. (1997, November 17). Joint purchasing pursued by alliances. Aviation Week and Space Technology, 65-

Porter, M. E. (1980). Competitive strategy: Techniques for analyzing industries and competitors. New York: Free

Press.

Porter, M. E. (1985). Competitive advantage: Creating and sustaining superior performance. New York: Free Press.

Service: Transportation prognosis 1998. (1998, January 12). BusinessWeek, 118.

Shay, Lee Ann (1999, January). Technician Shortage. Aviation Maintenance, 12-14.

United States Department of Transportation and FAA report of the Pilot and Aviation Maintenance Technician Blue Ribbon Panel. (1993, August). Pilots and aviation maintenance technicians for the 21st century: An assessment of availability and quality. 